\title{
GREEN SYNTHESIS OF TITANIUM AND ZINC OXIDE NANOPARTICLES FOR SIMULTANEOUS PHOTOCATALYTIC REMOVAL OF ESTROGENS IN WASTEWATER
}

\author{
*Muhammad YASIR, Tomáš ŠOPÍK, Hassan ALI, Dušan KIMMER, Vladimír SEDLAŘíK \\ Centre of Polymer Systems, University Institute, Tomas Bata University in Zlín, Zlín, Czech Republic, EU, \\ yasir@utb.cz
}

https://doi.org/10.37904/nanocon.2021.4333

\begin{abstract}
This study reports on the green synthesis of titanium and zinc oxide nanoparticles (ZnO-NPs) using lemon juice and peel extract, zinc acetate, ethylene glycol, and titanium IV isopropoxide as precursors. The prepared $\mathrm{TiO}_{2}$ and $\mathrm{ZnO}-\mathrm{NPs}$ were characterized via X-ray Diffraction analysis, UV-vis spectroscopy, dynamic light scattering, scanning electron microscopy, and EDAX. The as-prepared samples, $\mathrm{TiO}_{2}$ and $\mathrm{ZnO}-\mathrm{NPs}$, were further subjected for the photocatalytic degradation of estrogenic hormones (Estrone, Estradiol, Ethinylestradiol, and Estriol) under UV light irradiation at $365 \mathrm{~nm}$, which resulted in promising photocatalytic activity. All four hormones were significantly degraded owing to the photocatalytic activity combined with a slight contribution (4-11\%) from the hormonal adsorption onto the surface of the photocatalysts. Overall hormonal degradation rates in the range of $84-93 \%$ and approximately $99 \%$ were achieved in 60 minutes under UV light irradiation by $\mathrm{ZnO}$ and $\mathrm{TiO}_{2}$, respectively.
\end{abstract}

Keywords: Wastewater treatment, effluents, contraceptive, estrogen degradation, nanoparticles, green synthesis, liquid chromatography, HPLC

\section{INTRODUCTION}

Over the past several decades, the scarcity of clean water has increased with the rising demand for treated wastewater due to the ever-growing human population. Water pollution due to toxic chemical effluents such as estrone (E1), $\beta$-estradiol (E2), 17a-ethinylestradiol (EE2), and estriol (E3) steroid hormones, also known as endocrine-disrupting chemicals, is a serious threat to marine life, humans, and animals present in the environment [1]. Significantly high potencies of these hormones have been reported in water streams [2]. Such levels are being monitored to control the toxicity tolerance of these effluents at wastewater treatment plants $[3,4]$. In the Czech Republic, steroid hormones in the concentration range of 3.4-41 $\mathrm{ng} / \mathrm{L}$ have been detected in wetlands [5]. Synthetic hormone such as EE2 is most commonly used in oral contraceptive pills, although it is also used for the treatment of menstrual problems and prostate cancer. Due to the hormonal metabolites interaction in nature and their subsequent de-conjugation after the partial breakdown at sewage facilities, they become active again, and their remnants are also of significant contamination source in the environment $[6,7]$. These medicines have long-lasting adverse effects on living creatures when released in water sources [8]. Fertility disorder, rapid fish femininity, and testicles weight loss in Japanese quails are some of its consequences [9]. Similar impacts, such as the drop in male sperm count, higher risk of breast and ovarian cancer, have also been observed in humans [10]. Therefore, in this regard, immediate remediation of such toxic pollutants and their disposal is considered an environmental urgency. Conventional water treatment techniques are either less efficient for total toxicants removal or require other sophisticated methods for purification, usually high in energy and cost. In this context, photocatalytic degradation is the most promising strategy for environmental pollutants remediation due to simplicity, ease of operation, cost, and environmental sustainability. Photocatalysis has been successfully used in various other applications such as fuel production, antimicrobial activity, hydrogen production, and nitrogen fixation $[11,12,13]$. Two of the most commonly used photocatalysts to date are $\mathrm{ZnO}$ and $\mathrm{TiO}_{2}$, each possessing superior chemical stability and photocatalytic 
activity over the UV light range. However, it is essential to adopt a green synthesis approach with minimal environmental impact in regard to their synthesis. Lemon peels contain citric acid, which can act as a reducing agent in the green synthesis of $\mathrm{TiO}_{2}$-NPs. Whereas esterification occurs when citric acid in lemon extract mixes with ethylene glycol at $90^{\circ} \mathrm{C}$. A stable and soluble chelate complex of $\mathrm{Zn}$ is formed in the solution. When the solution is evaporated, $\mathrm{Zn}^{2+}$ ions uniformly bind to the active available binding sites of precursor resin, and this precursor breaks when calcinated to form ZnO-NPs. Therefore, it can be a useful green approach for making such NPs.

This study reports on the green synthesis and characterization of $\mathrm{ZnO}$ and $\mathrm{TiO}_{2}-\mathrm{NPs}$, which are highly efficient in the photocatalytic degradation removal of estrogenic hormones, simultaneously in a one-step using highperformance liquid chromatography (HPLC).

\section{MATERIALS AND METHODS}

\subsection{Materials and reagents}

The estrogenic hormones: E1 $\geq 99 \%$, E2 $\geq 98 \%$, E3 $\geq 97 \%$, and EE2 $\geq 98 \%$ were purchased from Sigma Aldrich Chemie $\mathrm{GmbH}$, Germany. The HPLC grade solutions: acetonitrile, and ethanol were purchased from Honeywell and VWR, Czech Republic, respectively. Deionized water $(\mathrm{pH} 7.3,18.3 \mathrm{M} \Omega / \mathrm{cm})$ was sourced from Milli-Q ultra-pure water purification system, Biopak ${ }^{\circledR}$ Polisher, Merck, USA. Glass microfiber (GMF) filters (Whatman, Czech Republic) with pore size $0.45 \mu \mathrm{m}$ and $25 \mathrm{~mm}$ diameter were used prior to HPLC. The primary precursor of $\mathrm{ZnO}$ is zinc acetate dihydrate $\geq 99.5 \%$, purchased from Fisher Scientific, U.K, and Sigma Aldrich's titanium IV isopropoxide (TTIP) for $\mathrm{TiO}_{2}$, which has a purity of $>99.5 \%$. Ethylene glycol was purchased from VWR, Czech Republic. For the bio-mediated synthesis, fresh and clean lemon peels (Citrus limon) were sliced into roughly $2 \mathrm{~cm}^{2}$ area pieces. All reagents were used without further purification.
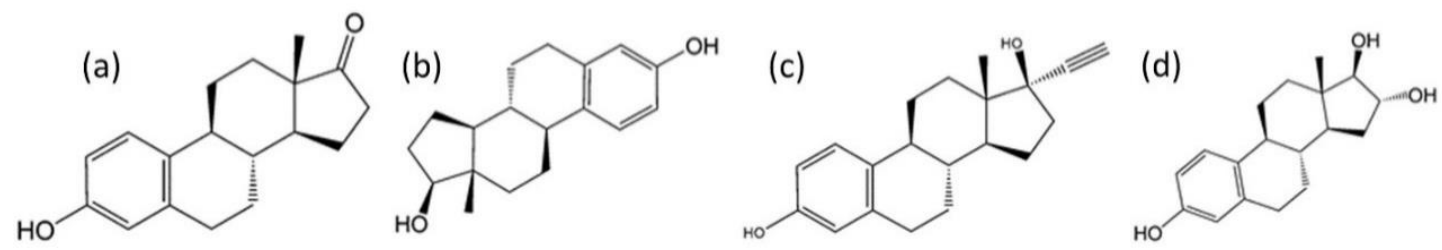

Figure 1 Steroid estrogenic hormones a) E1, b) E2, c) EE2, d) E3

\subsection{Synthesis of $\mathrm{ZnO}$ and $\mathrm{TiO}_{2} \mathrm{NPs}$}

For ZnO-NPs synthesis, $20 \mathrm{~mL}$ of ethylene glycol was taken, and $2.5 \mathrm{~g}$ of zinc acetate was uniformly dissolved with constant stirring. Lemons were purchased from the market and thoroughly cleaned before peeling. They were hand-squeezed for juice while solid particles and seeds were filtered off through common lab filter paper. The precursor solution was vigorously stirred at $1200 \mathrm{rpm}$, and the clean lemon extracted juice was drop-wise added with the help of a micropipette over a $1 \mathrm{~h}$ period. The solution was further stirred at $90{ }^{\circ} \mathrm{C}$ for $3 \mathrm{~h}$ using a preheated oil bath to obtain a yellowish gel. It was dried in a vacuum for $2 \mathrm{~h}$ at $110^{\circ} \mathrm{C}$. Afterward, the obtained product was calcinated for $2 \mathrm{~h}$ at $700^{\circ} \mathrm{C}$ in the muffle furnace to obtain $\mathrm{ZnO}$ nanoparticles which were crushed to have uniform fine particles without agglomeration.

$\mathrm{TiO}_{2}-\mathrm{NPs}$ were also produced by green synthesis. Initially, lemon peel extract was obtained by boiling $50 \mathrm{~g}$ of lemon peels in $150 \mathrm{ml}$ of distilled water at $90 \pm 3^{\circ} \mathrm{C}$ for $2.5 \mathrm{~h}$ while swirling magnetically at $400 \mathrm{rpm}$. The extract was combined with a $1.5 \mathrm{~N}$ TTIP solution in the following proportions: A mixture of $68 \mathrm{~mL}$ TTIP solution and $55 \mathrm{~mL}$ extract was used to prepare the sample. The lemon extract had a pH of 4.5 and TTIP of 5.5; both were brought to a pH of 5 before mixing. The sample was agitated at $700 \mathrm{rpm}$ for $3 \mathrm{~h}$, then centrifuged to separate the aqueous phase. The precipitated sample was then dried at $100{ }^{\circ} \mathrm{C}$ for $8 \mathrm{~h}$ and calcined at $700{ }^{\circ} \mathrm{C}$ for $2 \mathrm{~h}$ in a muffle furnace to obtain $\mathrm{TiO}_{2}-\mathrm{NPs}$ powder. 


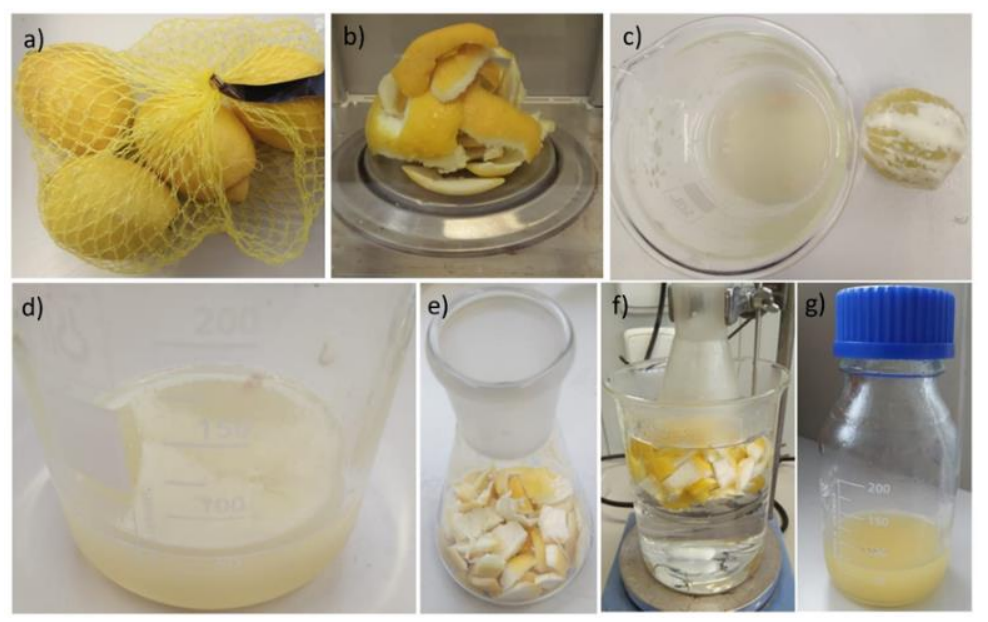

Figure 2 a) Collection of lemons from the market, b) waste lemon peels, c) hand-squeezed extracted juice from lemon, d) filtered juice, e) peels cut into small pieces, f) peels boiled and continuously stirred, g) extract collected from boiled peels

\subsection{Characterization}

Different analytical techniques were deployed to characterize the samples. Morphological analysis was carried out using Nova 450 scanning electron microscope (SEM) (FEI, Thermo Fisher Scientific, USA) via a throughthe-lens detector (TLD) at 5-10 kV applied potential and additionally equipped with Octane plus energy dispersive X-ray (EDX) spectroscopy (EDAX, Ametek Inc., PA, USA). X-ray diffractogram (XRD) of NPs was recorded using Miniflex ${ }^{\mathrm{TM}} 600 \mathrm{X}$-ray diffractometer (Rigaku, Japan), with $\operatorname{CoK}_{\beta}(\lambda=1.79 \AA)$ as a source. The angle $2 \theta$ was in the range from $3-90^{\circ}$ with operating current, step size, step time, and operational voltage set to $15 \mathrm{~mA}, 0.02^{\circ}, 10^{\circ} \mathrm{s}$, and $40 \mathrm{kV}$, respectively. The obtained diffractograms using Co source were converted to $\mathrm{Cu}$ using PowerDLL software converter 2.93 to compare data in the literature. Zetasizer Nano ZS (Malvern Instruments, Malvern, UK) was used to determine the particle size distribution with diiodomethane as a dispersant at ambient temperature and viscosity of $2.6 \mathrm{cP}$. The UV-vis absorption of the as-prepared NPs was conducted with the UV-vis spectrometer LAMBDA 1050+ (PerkinElmer, UK). The estrogenic hormones concentration was simultaneously quantified and recorded on HPLC DionexUltiMate 3000 Series (Thermo Fisher Scientific, Germany), using the method devised by Yasir et al. The limit of detection and quantification were found to be 0.560 and $1.867,1.189$ and 3.963, 0.920 and 3.067, and 1.883 and $6.280 \mu \mathrm{g} / \mathrm{L}$ for E3, E2, EE2, and E1, respectively [14].
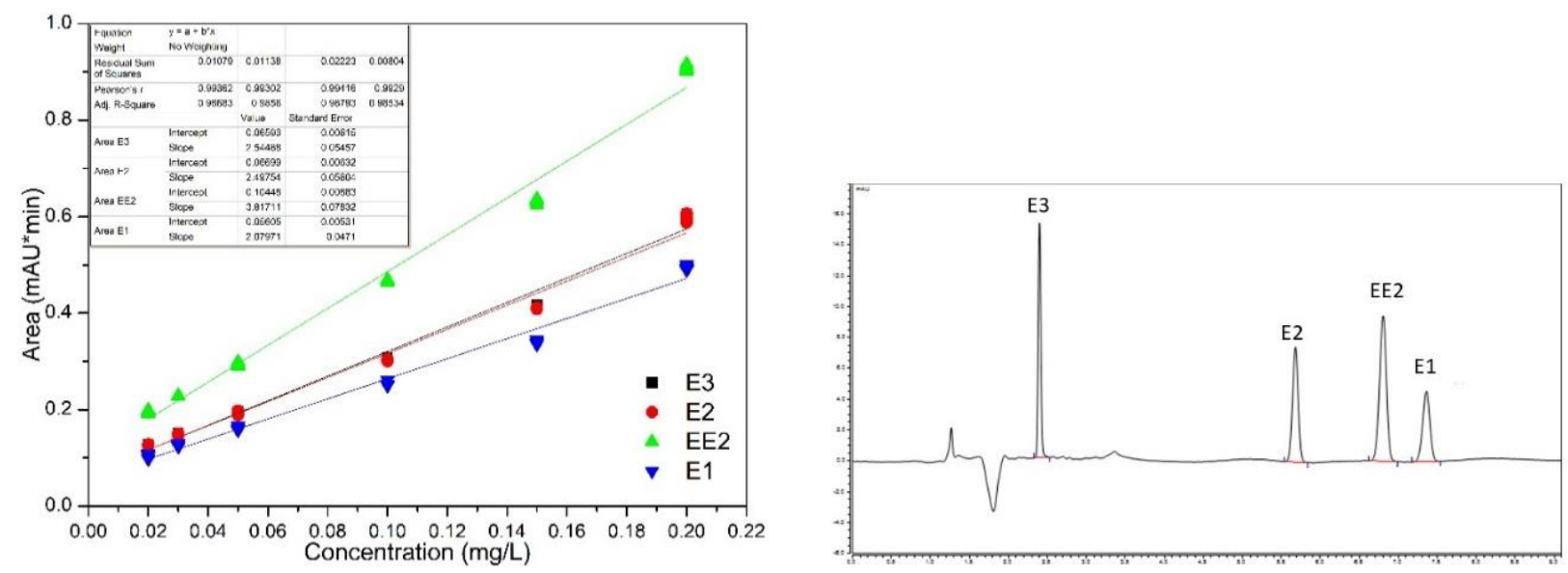

Figure 3 Calibration curve and chromatogram for estrogenic hormones (E1, E2, EE2, E3) 


\subsection{Photocatalytic degradation}

The photocatalytic degradation was conducted with the synthesized $\mathrm{ZnO}$ and $\mathrm{TiO}_{2}$ nanogranules $(5 \mathrm{mg})$ and $10 \mathrm{~mL}$ hormone solution $(0.8 \mathrm{mg} / \mathrm{L})$ under UV lamp irradiation at $365 \mathrm{~nm}$ with continuous stirring at $450 \mathrm{rpm}$. After $60 \mathrm{~min}$, the samples were drawn from the solution, the catalyst was removed by centrifuging at 14000 $\mathrm{rpm}$, and the remaining concentration of hormones in the solution was monitored using HPLC. A separate beaker without NPs was used as a control. The degradation efficiency is defined by equation (1).

Degradation removal $(\%)=\frac{C_{i}-C_{t}}{C_{i}} \times 100$

Where $C_{i}$ is the initial concentration $(\mathrm{mg} / \mathrm{L})$ and $C_{t}$ is the solution concentration at time $t(\mathrm{mg} / \mathrm{L})$.

\section{RESULTS AND DISCUSSION}

\subsection{Characterization of adsorbents}

Figure 4 below shows the appearance, surface morphology, and elemental analysis of NPs.

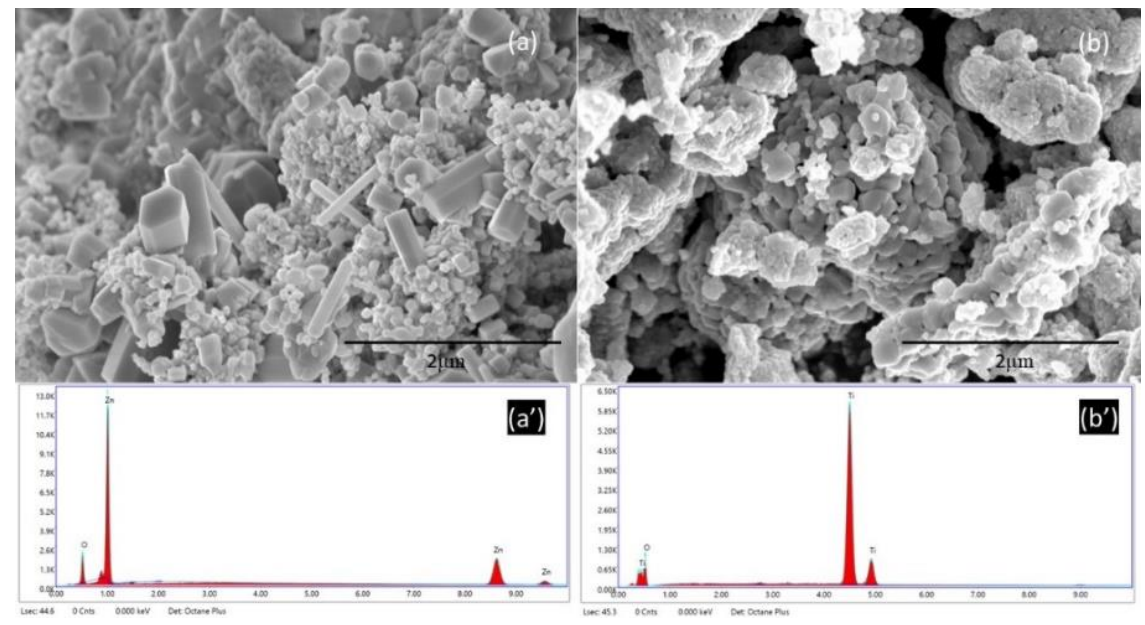

Figure 4 SEM micrographs and EDAX spectrum of, (a and $\left.a^{\prime}\right)$ ZnO-NPs, (b and b') TiO $2-N P s$, respectively

Figure 4a displays two distinguished types of ZnO-NPs, the cubic shaped with diameter $\sim 50 \mathrm{~nm}$, and hexagonal rods $\sim 100-250 \mathrm{~nm}$, length $\sim 900-1100 \mathrm{~nm}$. In Figure 4a' the peak at $0.55 \mathrm{keV}$ for O (wt.\% 6.51 and at.\% 22.15), and $\mathrm{Zn}$ at 1.00 , and $8.60 \mathrm{keV}$ represent wt.\% 93.49 and at.\% 77.85 . Figure $4 \mathrm{~b}$ demonstrates $\mathrm{TiO}_{2}-\mathrm{NPs}$; the NPs varied in size less than $100 \mathrm{~nm}$, and also some NPs on agglomerates can be seen. Figure $4 \mathbf{b}^{\prime}$ ' characteristic peaks at $0.4,4.5$, and $4.9 \mathrm{keV}$ for Ti (wt.\% 77.71 and at.\% 53.80), while at $0.5 \mathrm{keV}$ for $\mathrm{O}$ (wt.\% 22.29 and at.\% 46.20). The elemental analysis proves that no traces of any other element was found, and the synthesized NPs were pure.

Figure 5a displays the diffractogram of $\mathrm{ZnO}$ and $\mathrm{TiO}_{2}-\mathrm{NPs}$. The sharp intensity peaks at $2 \theta$ with miller indices were 31.7 (100), 34.4 (002), 36.2 (101), 47.4 (102), 56.5 (110), 62.8 (103), 66.2 (200), 67.8 (112), 68.9 (201), and 72.5 (004). These characteristic peaks represent the hexagonal structure of $\mathrm{ZnO}$ matching with DB card: 01-080-0075. For $\mathrm{TiO}_{2}$, characteristic peaks at 25.3 (101), 36.9 (103), 37.7 (004), 38.5 (112), 48.0 (200), 53.8 (105), 55.0 (211), 62.1 (213), 62.6 (204), 68.7 (116), and 70.2 (220) represent anatase phase (DB card: 01071-1166) while peaks at 27.4 (110), 36.0 (101), 39.1 (200), 41.2 (111), 44.0 (210), 54.3 (211), 56.6 (220), 62.6 (002), 64.0 (310), 68.9 (301), and 69.8 (112) show rutile phase matching DB card: 01-086-0148. The calculated average particle size values for $\mathrm{ZnO}$ and $\mathrm{TiO}_{2}$ from the well-known Debye-Scherrer formula are 33.32 and $45.85 \mathrm{~nm}$, respectively. Figure $5 \mathbf{b}$ shows ZnO-NPs size in the range of 900-1100 nm, which can be 
the length of hexagonal rods that are in good compliance with the results from SEM and Figure 5c presents $\mathrm{TiO}_{2}$-NPs size density peak at $\sim 60 \mathrm{~nm}$; similar particle size is also evident from SEM micrograph.
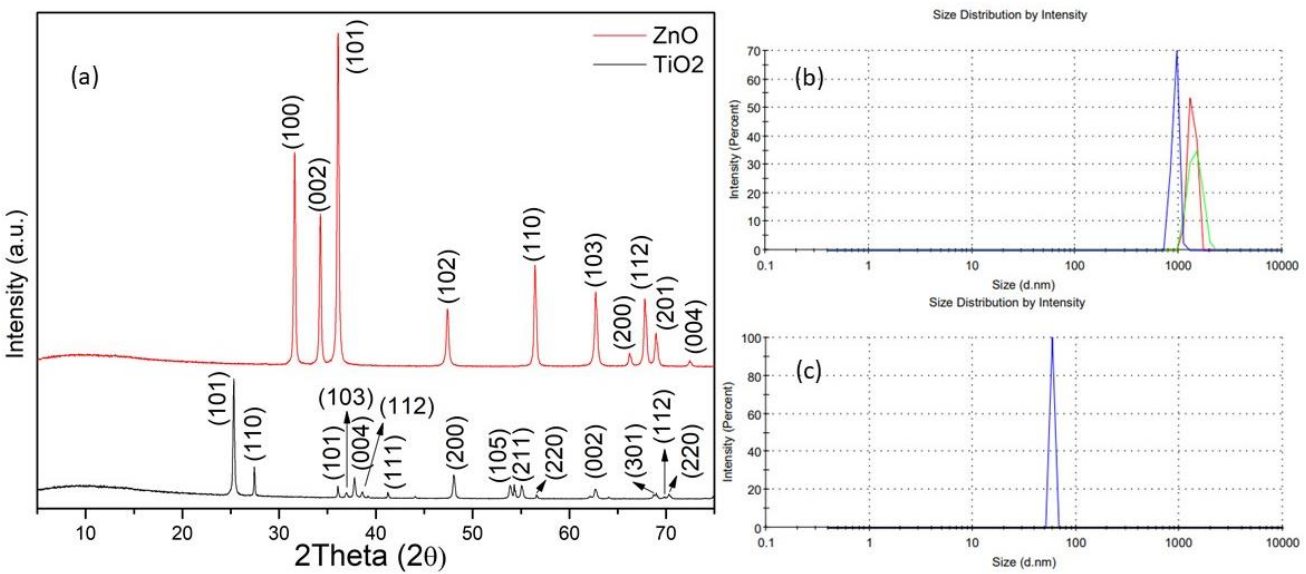

Figure 5 (a) X-ray diffraction pattern of green synthesized $\mathrm{ZnO}$ and $\mathrm{TiO}_{2}-\mathrm{NPs}$, the particle size distribution of (b) $\mathrm{ZnO}-\mathrm{NPs}$, and (c) $\mathrm{TiO}_{2}-\mathrm{NPs}$

\subsection{UV-vis diffuse reflectance spectroscopy and degradation mechanism}

The factor that plays a crucial role in photoactivity and optical properties is the electronic structure associated with its bandgap. The as-prepared $\mathrm{ZnO}$ and $\mathrm{TiO}_{2}$ samples were characterized by UV-vis spectroscopy to determine the optical bandgaps using the Kubelka-Munk equation (2).

$[F(R) . h v]^{1 / 2}=[h v-E g]$

By plotting the line of best fit on $[F(R) \cdot h v] 1 / 2$ vs. $h v$ graph gives the optical bandgap energy values using the extrapolation of its slope to $F(R) \rightarrow 0$, as shown in Figure 6 .
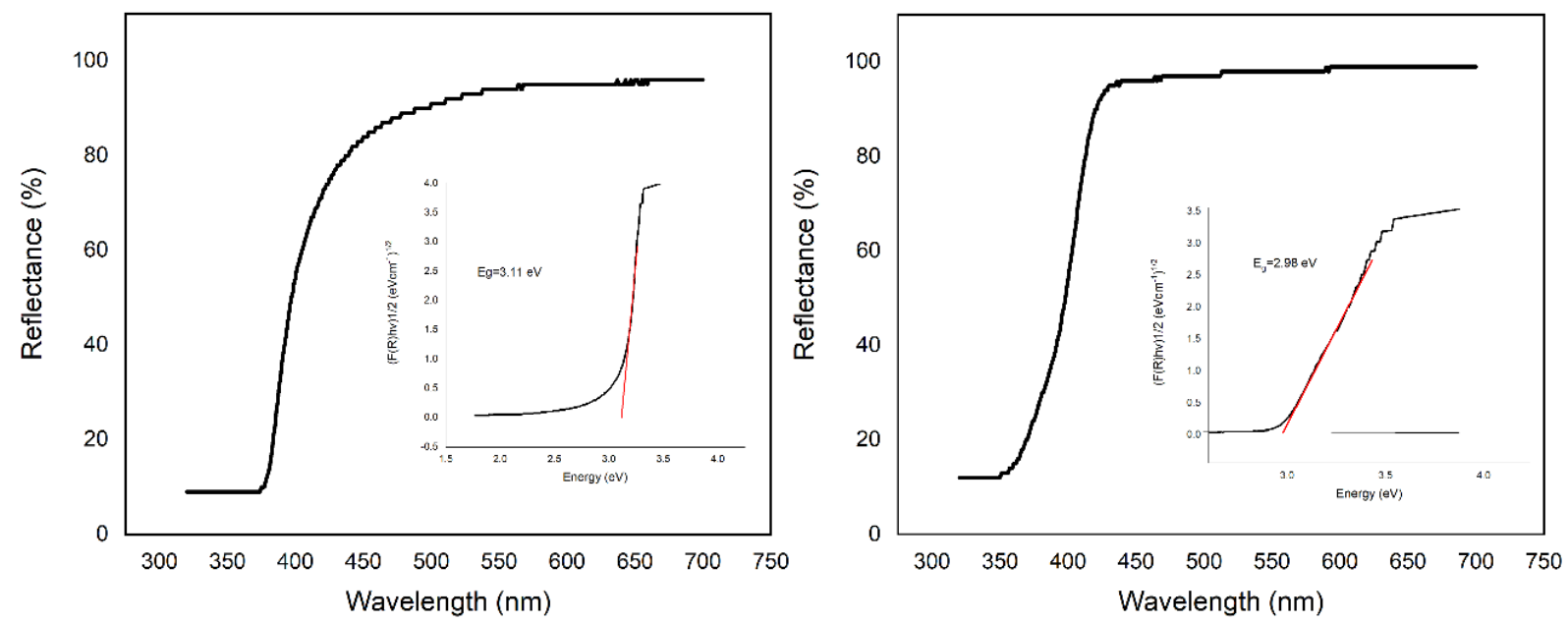

Figure $6[\mathrm{~F}(\mathrm{R}) \cdot \mathrm{hv}] 1 / 2$ vs. hv graph for $\mathrm{ZnO}$ (left) and $\mathrm{TiO}_{2}$ (right)

Optical bandgap values of 2.98 and $3.11 \mathrm{eV}$ were obtained for the $\mathrm{TiO}_{2}$ and $\mathrm{ZnO}$, respectively. The obtained values are similar to the bandgap values reported in the literature. However, for the $\mathrm{TiO}_{2}$ sample, a blueshift in the wavelength is observed, due to which the bandgap decreased from the typically reported value of 3.2 to $2.98 \mathrm{eV}$. This indicates that the as-prepared $\mathrm{TiO}_{2}$ sample possesses the ability to excite electrons even in the visible light range. 
The as-prepared $\mathrm{TiO}_{2}$ and $\mathrm{ZnO}$ samples exhibited superior photocatalytic performance towards hormones degradation. A schematic illustration of the proposed photocatalytic mechanism is given in Figure 7. Since $\mathrm{TiO}_{2}$ and $\mathrm{ZnO}$ are two of the most commonly investigated photocatalytic semiconducting materials, their degradation mechanism is well established in the literature. A near-total degradation was achieved by the following process, i.e., (i) electronic excitation to the conduction after absorbing photons with energy higher than the bandgap (ii) formation of holes in the valence band (iii) participation of the excited electrons and holes in water to produce highly reactive radicals. The produced reactive species such as $\cdot \mathrm{OH}, \cdot \mathrm{O}^{2-}$ possess the strong oxidizing ability and were able to degrade the organic hormones adsorbed onto the surface of the photocatalysts.
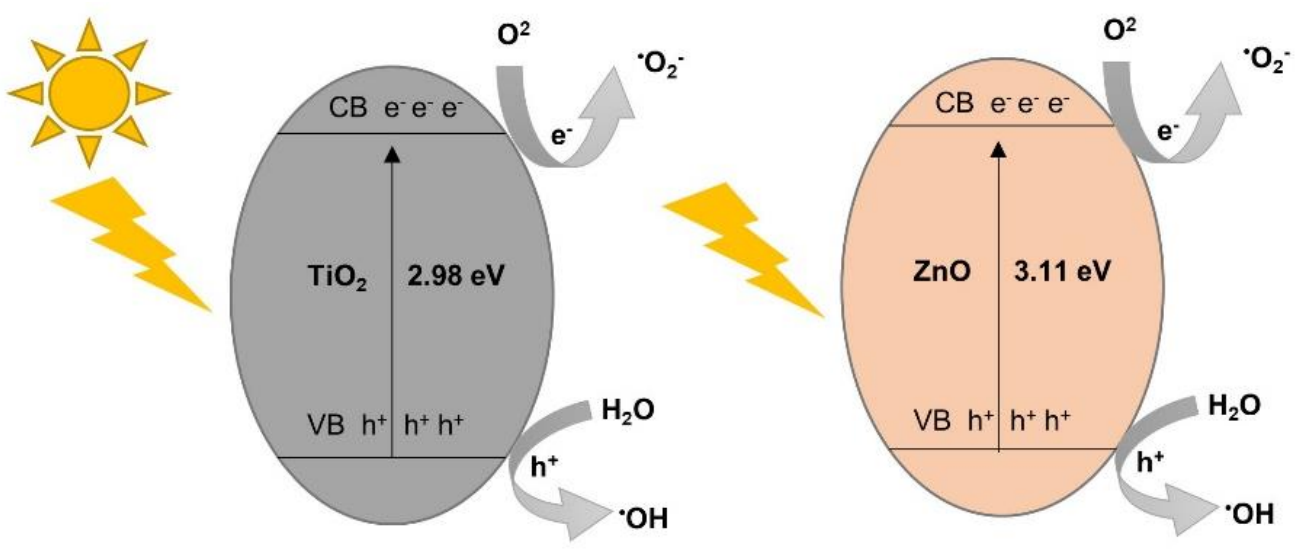

Figure 7 Degradation mechanism of $\mathrm{TiO}_{2}$ and $\mathrm{ZnO}-\mathrm{NPs}$

Simultaneous adsorption and photocatalytic degradation removal of four estrogenic hormones were determined, as shown in Figure 8.

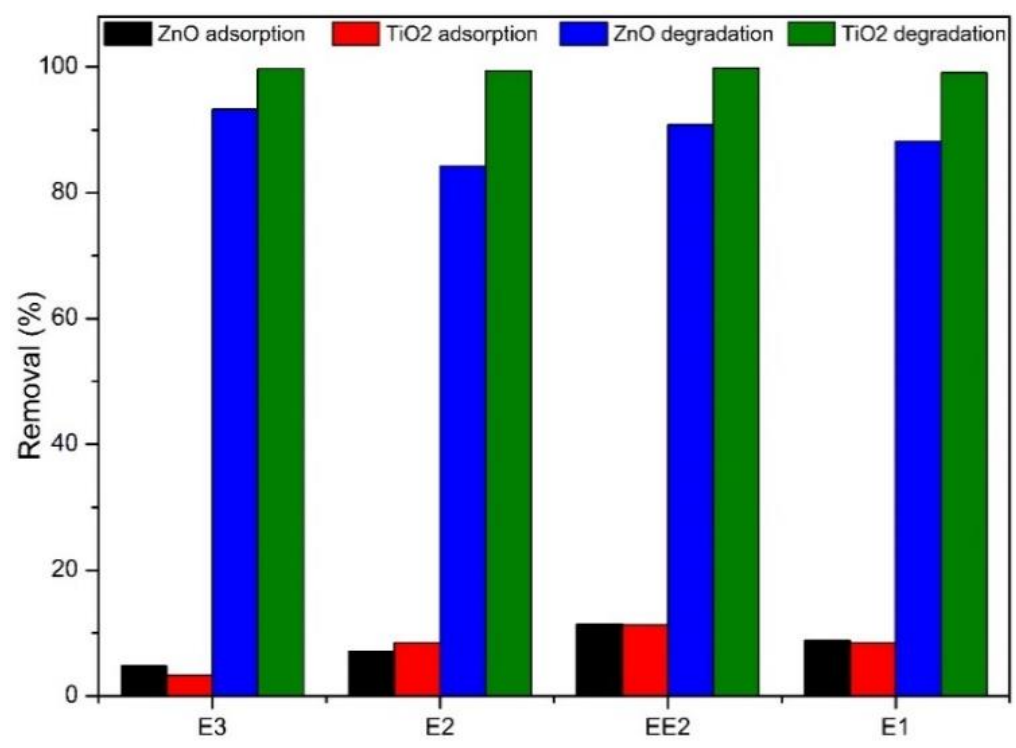

Figure 8 Adsorption and UV-Photocatalytic degradation of steroid estrogen hormones in $1 \mathrm{~h}$ time

It can be seen that the adsorption of each hormone is almost similar and nearly equal on both types of NPs. However, the difference is evident in degradation. $\mathrm{TiO}_{2}$ is more efficient than $\mathrm{ZnO}-\mathrm{NPs}$ for each hormone reaching approximately $99 \%$ degradation in $60 \mathrm{~min}$. Also, $\mathrm{ZnO}$ has the highest degradation for $\mathrm{E} 3(93 \%)$ with the least adsorption (4\%), while EE2 has the highest adsorption (11\%) and photodegradation with $\mathrm{TiO}_{2}$. 


\section{CONCLUSION}

The green synthesized $\mathrm{ZnO}$ and $\mathrm{TiO}_{2}-\mathrm{NPs}$ were successfully prepared from lemon extract and peels. The Xray diffractograms determined the phases, particle size, and EDAX elemental analysis confirmed the purity of NPs. The NPs achieved a rapid photodegradation tendency with overall hormonal degradation in the range of $84-93 \%$ by $\mathrm{ZnO}$ and approximately $99 \%$ by $\mathrm{TiO}_{2}$ in 60 min under UV light irradiation. In the future, these NPs can be used as additives in nanofiber modification for enhanced adsorption and photodegradation of dyes, other steroid hormones, and micro-pollutants in wastewater.

\section{ACKNOWLEDGEMENTS}

\section{The authors gratefully acknowledge the financial support by the Ministry of Education, Youth, and Sports of the Czech Republic (grant no. RP/CPS/2020/002) and the Internal Grant Agency, IGACPS2021002 from the Centre of Polymer System (CPS), Tomas Bata University in Zlin, Czech Republic.}

\section{REFERENCES}

[1] SCHÄFER, A.I., STELZL, K., FAGHIH, M., SEN GUPTA, S., KRISHNADAS, K. R., HEIßLER, S., PRADEEP, T. Poly(ether sulfone) Nanofibers Impregnated with $\beta$-Cyclodextrin for Increased Micropollutant Removal from Water. ACS Sustainable Chemistry and Engineering. [online]. 2018, vol. 6, no. 3, pp. 2942-2953. Available from: https://doi.org/10.1021/acssuschemeng.7b02214.

[2] CARTINELLA, J. L., CATH, T. Y., FLYNN, M. T., MILlER, G. C., HUNTER, K. W., CHILDRESS, A. E. Removal of natural steroid hormones from wastewater using membrane contactor processes. Environmental Science and Technology. [online]. 2006, vol. 40, no. 23, pp. 7381-7386. Available from: https://doi.org/10.1021/es060550i.

[3] JOHNSON, A. C., AERNI, H. R., GERRITSEN, A., GIBERT, M., GIGER, W., HYLLAND, K., JÜRGENS, M., NAKARI, T., PICKERING, A., SUTER, M. J. F., SVENSON, A., WETTSTEIN, F. E. Comparing steroid estrogen, and nonylphenol content across a range of European sewage plants with different treatment and management practices. Water Research. [online]. 2005, vol. 39, no. 1, pp. 47-58. Available from: https://doi.org/10.1016/j.watres.2004.07.025.

[4] SARMAH, A. K., NORTHCOTT, G. L., LEUSCH, F. D. L., TREMBLAY, L. A. A survey of endocrine disrupting chemicals (EDCs) in municipal sewage and animal waste effluents in the Waikato region of New Zealand. Science of the Total Environment. [online]. 2006, vol. 355, no. 1-3, pp. 135-144. Available from: https://doi.org/10.1016/j.scitotenv.2005.02.027.

[5] VYMAZAL, J., BŘEZINOVÁ, T., KOŽELUH, M. Occurrence and removal of estrogens, progesterone and testosterone in three constructed wetlands treating municipal sewage in the Czech Republic. Science of the Total Environment. [online]. 2015, vol. 536, pp. 625-631. Available from: https://doi.org/10.1016/i.scitotenv.2015.07.077.

[6] HAN, J., QIU, W., CAO, Z., HU, J., GAO, W. Adsorption of ethinylestradiol (EE2) on polyamide 612: Molecular modeling and effects of water chemistry. Water Research. [online]. 2013, vol. 47, no. 7, pp. 2273-2284. Available from: https://doi.org/10.1016/j.watres.2013.01.046.

[7] LIMPIYAKORN, T., HOMKLIN, S., ONG, S. K. Fate of estrogens and estrogenic potentials in sewerage systems. Critical Reviews in Environmental Science and Technology. [online]. 2011, vol. 41, no. 13, pp. 1231-1270. Available from: https://doi.org/10.1080/10643380903488680.

[8] CHEN, Y., ZHANG, Y., LUO, L., SHI, Y., WANG, S., LI, L., LONG, Y., JIANG, F. A novel templated synthesis of $\mathrm{C} / \mathrm{N}$-doped $\beta$-Bi2O3 nanosheets for synergistic rapid removal of $17 \alpha$-ethynylestradiol by adsorption and photocatalytic degradation. Ceramics International. [online]. 2018, vol. 44, no. 2, pp. 2178-2185. Available from: https://doi.org/10.1016/j.ceramint.2017.10.173.

[9] NGHIEM, L. D., SCHÄFER, A. I. Adsorption and transport of trace contaminant estrone in NF/RO membranes. Environmental Engineering Science. [online]. 2002, vol. 19, no. 6, pp. 441-451. Available from: https://doi.org/10.1089/109287502320963427. 
[10] SOLOMON, G. M., SCHETTLER, T. Environment and health: 6. Endocrine disruption and potential human health implications. Cmaj. 2000, vol. 163, no. 11, pp. 1471-1476.

[11] ALI, H., GULER, A. C., MASAR, M., URBANEK, P., URBANEK, M., SKODA, D., SULY, P., MACHOVSKY, M., GALUSEK, D., KURITKA, I. Solid-state synthesis of direct z-scheme cu2o/wo3 nanocomposites with enhanced visible-light photocatalytic performance. Catalysts. [online]. 2021, vol. 11, pp. 1-26. Available from: https://doi.org/10.3390/catal11020293.

[12] DJURIŠıĆ, A. B., HE, Y., NG, A. M. C. Visible-light photocatalysts: Prospects and challenges. APL Materials. [online]. 2020, vol. 8, no. 3. Available from: https://doi.org/10.1063/1.5140497.

[13] ALI, H., MASAR, M., GÜLER, A. C., URBÁNEK, M., MACHOVSKY, M., KUŘITKA, I. Heterojunction-based photocatalytic nitrogen fixation: Principles and current progress. Nanoscale Advances. [online]. 2021. Available from: https://doi.org/10.1039/D1NA00565K.

[14] YASIR, M., ŠOPÍK, T., KIMMER, D., SEDLAŘíK, V. Facile hplc technique for simultaneous detection of estrogentic hormones in wastewater In: NANOCON 2020 Conference Proceedings. [online]. Brno: Nanocon, 2020, pp. 272-276. Available from: https://doi.org/10.37904/nanocon.2020.3710. 